\title{
Power, Public Authority, and Place: The Changing and Critical Role of the Architectural Profession
}

\author{
PETER WEBBER \\ University of Sydney \\ Australia
}

\begin{abstract}
The paper examines the nature of the power structure in a large metropolitan city, as it relates to the role of the architectural profession in the urban development process. The increasingly complex regulatory and technological influences generate interactive processes in the case of large development projects; these are reviewed in the case of three projects in Sydney - the Olympic 2000 site, Circular Quay East adjoining the Opera House, and the Casino. The paper addresses the implications for architectural education of contemporary processes, and whether, in the words of the conference chair, they have contributed to a "subverting" of the conventions of place.
\end{abstract}

\section{INTRODUCTION}

One of the provocative observations with which the distinguished social historian, Fernand Braudel, concluded the first volume of his monumental "Civilization and Capitalism" series, a little less than twenty years ago was:

... that every great centre of population has worked out a series of elementary answers - and has an unfortunate tendency to stick to them out of that force of inertia which is one of the great artisans of history.'

Written from a Euro-centric position this perception must be seriously questioned today in the context at least of 'new world' civilizations. The succeeding years have seen increasing disturbance to the "inertia", - if one of the measures of social change is the 'answers' which are written in the changing physical urban fabric of large metropolitan cities.

This paper examines the evolving nature of the power structure in Sydney as it relates to the role of the architectural profession in the development process. Three large urban development projects presently at advanced stages of planning and design are overviewed for the purpose of exploring the responsibilities for decisions about their urban and architectural form. Two of the projects are very large developments in the CBD, - a residential and commercial complex adjacent to the Opera House, and a casino with its many associated activities, - and the third is the main site for the events of the year 2000 Olympic Games. The analysis tends to support the assertion of the conference chair that:

The traditional territories occupied by politicians, bankers, developers, bureaucrats and other entities that control the production of space are evolving and changing at an accelerating pace, transcending material boundaries, collapsing time, and perhaps undermining/redefining the roles that various professions play in society. ${ }^{2}$

\section{CONTEXT}

Sydney today is a large metropolitan city with a population of over 3.7 million, projected to grow to 4.5 million in the early years of the 21 st century. ${ }^{3}$ It has a compact high-rise core of commercial, administrative and cultural activities, a series of growing regional sub-centres, and low-density, largely single-family, residential areas which spreads fifty kilometres and more to the south, north and west.

The nature of the design and development process for large urban projects has been subject to major changes within the last two decades. With the increasingly large scale of building and internationalisation of both investment and design strategies, has come a demand for more intensive control and management of projects on the part of investors, and demand for greater accountability in terms of environmental and ecological impact on the part of the community through their elected representatives.

From the viewpoint of the investor, - whether a commercial corporation or public body - , the most typical strategy has become the establishment of a project management organisation. The project manager sometimes assumes not only the responsibility for design and construction, but also for financing, operation and management of a project. The project manager commissions architectural and other consultants to provide full or partial design services. Architects characteristically in this situation do not have direct responsibility to the owner for whom the building is to be constructed, nor necessarily the authority to direct and coordinate engineering and other design consultants. The project manager may be a building construction company or a 
management consultant, - sometimes without particular experience of the building industry.

Whilst for small projects architects more usually still retain direct responsibility to clients for total design and construction supervision, this essentially 19th Century and early 20th Century model of the architect as master of the entire process is now almost an anachronism for buildings of large size. In this new environment architects increasingly are themselves forming development companies and becoming members of boards of existing large development organisations. This heralds a return to the traditional pre19 th Century role, when the work of architects such as John Nash in England and countless others before him was characterised by the architect acting as initiator, manager and designer of major urban projects, as well as working directly for wealthy patrons. Surveys of the profession in the U.K., U.S.A., and Australia suggest that these far more diversified roles are now commonplace at least in the English-speaking world. ${ }^{4}$

From the viewpoint of a more articulate and well-informed community it has become necessary to put in place a fabric of measures designed to protect environmental amenity. Where previously it may have been sufficient to rely upon simple zoning codes, and building regulations there are now in most large cities far more complex and comprehensive procedures. ${ }^{5}$ In the State of NSW the original Environmental Planning and Assessment Act (1979) established a welcome statutory framework within which individual local statutory environmental plans are made. These are supplemented by development control codes and guidelines, - at least for areas of the central city, - which attempt to establish and codify that delicate and elusive balance between free choice and prescription. ${ }^{6}$

The development of urban design concepts and the drafting of the design controls has required new professional skills within both State and local authorities. Where previously staff with only engineering, land surveying or policy planning backgrounds managed city planning offices, it has been necessary to enlist architectural and urban design skills. The manager of the City of Sydney planning branch is now for the first time an architect-planner, and complementary skilled senior staff with architectural and urban design qualifications have been appointed. A considerable body of urban design expertise has evolved within State Government authorities and the large local government Councils and academic institutions. A somewhat similar pattern has emerged in Melbourne and other large Australian cities. Many of the individuals within these bodies in Sydney have been actively involved in the major projects outlined in the following three case studies.

\section{EAST CIRCULAR QUAY Background}

A considerable controversy was aroused by proposals to redevelop a narrow strip of post-war commercial buildings adjoining the site of that remarkable national icon, the Sydney Opera House. The properties were all in private ownership and were consolidated by a company which sought to build a monolithic structure covering all the sites, replacing the existing individual commercial structures. These are undistinguished buildings, but it is precisely this lack of distinction which meant that they presented no threat to the integrity of the image of the Opera House.

The sites were purchased for high values which reflected the floor space potential which city planning codes have permitted, but the large building bulk generated was very difficult to reconcile with environmental objectives for the site. A series of development proposals attracted vociferous opposition from both design and planning professionals and the general community, and were refused by City Council. A complex series of negotiations spanning several years has followed, resulting finally in approval in 1994 to revised proposals.

\section{Summary of process}

Exploratory proposals for redevelopment of the site were advanced during the late 1980's; in response, the Urban Design Unit of the State Government Department of Planning, - comprising staff architects and planners, - prepared preliminary urban design guidelines. The site was viewed as being of State and national importance, - justifying the intervention of the State authority in the process.?

- The Sydney City Council commissioned an architectural firm to undertake a detailed study and recommend design controls for the site. ${ }^{8}$

- The Central Sydney Planning Committee, on the recommendation of its staff, headed by the City Planner, - an architect, - adopted urban design guidelines based on the consultant's study, but considerably varying in detail.

- A development proposal which exceeded the guidelines was rejected. After extensive public debate an open ideas competition was held, assessed by a panel of expert assessors, - primarily independent architects, - who advised further modifications to the guidelines. ${ }^{9}$

- Amended urban design guidelines were prepared, exhibited, amended again in detail and finally adopted in August 1992. ${ }^{10}$

- Three architectural teams were commissioned to prepare preliminary proposals for the site.

- The developer commissioned one architectural consortium, - responsible to its project manager, - to prepare a development application which was finally approved in 1994."1

Throughout the entire process, complex negotiations continued, - involving the City Council, the State Government, and the Federal Government. The critical ingredients in the urban design controls as agreed were the imposition of absolute maximum and minimum height limits, extension of building width by integrating an area of public roadway into the development site, protection of certain view corridors, 
and specified locations of a pedestrian colonnade, vehicle free pedestrian areas, and vehicle access points. Three of the key negotiators were the City Planner and the manager of City Projects, and an elected member of the City Council, all of whom are architects.

\section{Conclusions}

Whilst the detailed architectural design of the project itself is proceeding within a management framework in which the architectural team is responsible to a project manager, rather than directly to the client, - this in turn is within a broader management context in which the primary design determinants have already been established. The formal adoption of the urban design guidelines is the responsibility of the elected Council as a whole, but their formulation was on the initiative of and largely at the direction of architects in elected or senior management positions.

\section{SYDNEY CASINO \\ Background}

This is a very large complex of buildings on a site of 3.4 hectares ( 8.4 acres) on the Pyrmont peninsula adjoining the Sydney CBD. The gaming facilities are a relatively small proportion of the total accommodation which will include a large hotel, serviced residential apartments, a 700 seat showroom theatre, a 2000 seat lyric theatre, twenty six licensed bars and restaurants, a retail arcade and food hall, and underground parking for 2500 vehicles. A new light rail service will run below the structure connecting the CBD to the casino and the peninsula.

The political and ethical issues involved with promotion of a gambling-oriented development caused predictably extended debate in the city. The siting of such a major development in a location characterised not only by declining and derelict industrial plant, but also by an alienated inner city lower-income community was controversial. The specific site chosen was occupied by a disused State-owned power generating station and has been leased to the casino operator for a 99 year term.

The Ultimo-Pyrmont peninsula was one of the first areas developed in the 19th Century for shipbuilding, waterfront and heavy industry with a working-class population which grew to about 30,000 people. With abandonment of industry and decline of population to less than 1800 people by the 1980 's the area was destined for major redevelopment.

\section{Summary of Process}

- A statutory plan was prepared for the Peninsula generally, covering zoning and strategic issues, as well as a development control plan nominating specific physical requirements such as heights, building alignment, open space, solar access, energy conservation and heritage conservation provisions. This was undertaken by planning staff and by an urban design group within the State Department of Planning under the direction of an archi- tect-planner. ${ }^{12}$

- Within the context of this "sub-regional" plan, Master Plans for major sites were required to be prepared before development proposals could be considered. In the case of the casino site, such a plan for Pyrmont Bay was undertaken by consultant architect-planners and duly adopted by the planning agency. With knowledge of the likely size and program for the casino, this plan nominated requirements for height, density and bulk, relationship to street form, pedestrian circulation, vehicular access and egress, accommodation for light rail facilities, and landscape. ${ }^{13}$

- Tenders were called for design, construction, financing and operation of the casino and associated facilities by the Casino Control Authority, the State authority which has responsibility for oversight and surveillance of Casino operations in the State. It established two advisory panels, one dealing with physical design, the other with finance and legal issues. The first was chaired by a full-time architectplanner, and membership included two other experienced architects, with an urban designer/architect advising on urban issues as necessary. The architect/ chairman of this panel also served on the finance and legal panel. ${ }^{14}$

- Bids were submitted by casino operators who each engaged architects for building design. Ultimately the field was narrowed to one favoured proposal which - on the advice of the expert panels - satisfied both architectural/ urban design, and financial criteria. Designs were developed in consultation with the expert panels. The favoured proposal was substantially amended in terms of the form of the tower buildings following public response to certain aspects of the proposal.

- The favoured proposal has now been accepted by the Casino Control Authority, approved by the planning authority and is proceeding to detailed design and construction phases. The architectural consultants, one of Sydney's largest and most accomplished firms, - in alliance with a US architectural organisation with experience in the details of casino operations - are responsible to and employed by the project management/construction company. ${ }^{15}$

\section{Conclusions}

At every stage of the process the development has proceeded within the general policy framework, and quite specific formal framework of design controls which have been formulated by architects, acting either in official capacities or as consultants. A critical emphasis throughout has been on the enhancement of the environment of Pyrmont and Pyrmont Bay. Although the architects commissioned for the project itself are beholden to the project managers, - who are building contractors and managers, - and are subject to their direction, - in the broader context the essential attributes of the proposal have been developed by the collective skills of experienced members of the architectural profession. 


\section{HOMEBUSH BAY OLYMPIC GAMES CENTRE Background}

The Homebush Bay area - about $12 \mathrm{~km}$ from the CBD of Sydney - is the location for the core sporting activities of the year 2000 Games in Sydney. It will accommodate the main stadium, athletic and swimming events, facilities for baseball, tennis, equestrian, hockey and cycling competitions, and residential accommodation for at least 15000 people. Previously the site was used for the purpose of an abattoir, a brickworks, waste disposal, a naval armaments depot and various industrial activities, with the result that there is substantial ground pollution, and pollution fo the adjacent waterways.

There are important adjoining natural areas which include remnant woodlands, saltmarsh wetlands, and mangrove wetlands. An important component of the Sydney bid for the Olympics was a commitment to environmental rehabilitation of degraded parts of the site, and an ecologically responsible approach to planning and design. Strategies for containment of pollutants, enhancement of natural areas, and ensuring good public transport access are intrinsic to the program. Prior to the bid a new wetland park had been developed adjoining the eastern boundary of the site, and certain sporting facilities had already been completed. The announcement of the allocation of the Games to Sydney presented the formidable task of planning, designing and constructing major new facilities within a short time-frame.

\section{Summary of Process}

Preparation of a bid for the 2000 Olympics was a complex organisational task, primarily the responsibility of State Government, with cooperation of City Council and the Federal Government. Of the many individuals involved in developing the material for the bid, arguably the most critical role was played by an architect who had been, - prior to 1988 , - a senior manager in the office of the NSW Government Architect. In various capacities he prepared the key papers covering the facility strategies, the competition strategies, and the green strategies for the Olympic bid. He acted for a time as the head of the Homebush Bay Corporation, the body charged with the responsibility of providing and managing the facilities, and is now the Executive Manager, Planning and Design, of the Sydney Olympic Games Organising Committee. ${ }^{16}$ This is effectively the client body representing the State Government.

- Planning and design for the site was undertaken by planning and architectural consultants in cooperation with the State Government's Property Services Group, as the project construction and management authority.

- During preparation of the Olympic bid statutory planning documents were prepared by the State Department of Planning, and a physical Structure Plan by the consultant architect/planners in collaboration with the Property Services Group, itself with a core project staff of an experienced planner and an architect. Following success of the bid a more detailed Masterplan was prepared using the same team. ${ }^{17}$

- An Urban Design Panel provided advice and assistance during this phase. Its composition comprised four architects with planning and urban design expertise, and one planner. ${ }^{18}$

- In late 1994 an intensive Design Studio took place involving eight teams of architects and other professional consultants, with distinguished international architects Jean Nouvel and Edith Girarde participating. Certain ideas emerging from the Studio may be influential in the future shaping of the project.

- As the final definitive stage of urban design and individual project design is now commencing, an Urban Design Group has been established. This is chaired by an architect, and includes four other architectural consultants and a landscape architect. The group will be responsible for the critical task of designing the urban and landscape context and coordinating the design of the individual components. ${ }^{19}$

- Several of the smaller facilities are already completed or at advanced stages of design or construction, but the main stadium, Olympic Village, and other sporting venues, remain to be resolved. These will be tendered to major consortia who will be responsible for design, construction, operation and financing. Here the architect's role will be restricted to that of consultant to the project management organisation of the bidding companies.

\section{Conclusions}

Overview of the management and organisational arrangements for developing the planning and design of this complex project reveals the pervasive roles of the architectural profession at all stages, and the particularly prominent role of one individual in the policy formulation and pre-design phase of the operation.

In the case of the design and construction of the individual major facilities which are yet to be finalised, the now more conventional role of the architect being answerable to a major management and construction company will apply, but as with the two other case studies described, the designs will be constrained within a pre-established urban design framework.

\section{IMPLICATIONS FOR THE EDUCATION OF ARCHITECTS}

Perhaps surprisingly in the context of the declining influence and subservient role played by architects in more conventional and less complex projects, analysis of these three case studies has demonstrated that in each case the roles and responsibilities of members of the architectural profession have been prominent if not predominant. It is clear that when a high order of design skills is required, to respond to novel and challenging situations of unusual nature, then the community, - through its various agencies and authorities, - has 
relied heavily upon architects, - many of them with dual qualifications in architecture and planning or urban design.

It is equally apparent in each of these cases that it has been the influence and authority of such architects in positions of public responsibility that has been critical to the process. In some cases individuals already occupied senior positions in City Council or State Government authorities, and in others architects in private practice or academic positions have been appointed to serve on executive or advisory boards, often on the recommendation of architects in public positions. The evidence of these case studies, together with the now well-established role played by architects in formulating urban design controls in cities throughout Australia raises the question of whether educational programs are at present sufficiently biased towards preparing graduates for roles of the type described. It might be argued that such preparedness can emerge only after extensive experience and the full maturity which comes after many years in practice, - but there is sufficient evidence to suggest that this is not entirely the case. Amongst the participants in the case studies described there are several who have had a little more or less than ten years of postgraduate experience. Numbers are not sufficient for a meaningful statistical analysis, but it may be significant that most have graduated from a school which has had a strong commitment to introducing broader social and urban design issues from the very beginning of its undergraduate programs, and persisting in the weaving of such strands into the fabric of the full program. ${ }^{20}$

Such insistence on the importance of the urban context, rather than merely the individual project is perhaps one of the most constructive outcomes of the many and diverse streams of post-modern discourse. The undergraduate programs in this same School were restructured in the 1970's to provide an initial three years which placed very strong emphasis upon environmental, social and contextual concerns: after a mandatory break for one year of practical experience, students electing to pursue architecture as a career return for the two-year professional architectural degree program. In the face of some criticism that there is less stress on formal and technical aspects than there may be in some other schools of architecture, the emergence of new roles for architects of the type described in this paper gives support to the view that the present emphasis is not only defensible but very desirable.

Postgraduate education and research too is clearly of critical importance. The abandonment of almost all physical design components in the curricula of very many of the urban and regional planning programs in UK, USA, - and not least in Australia, has left a vacuum. Planners trained within this regime, and mostly building upon foundation studies in law, sociology, economics, geography and the natural sciences, have made essential contributions to development of public policy at State, regional and local level, - but have been characteristically ill-equipped when confronted with the reality of designing the built environment. Such programs have been typically unattractive to architectural graduates who seek a design-oriented career, and very few have chosen this path in recent decades. Architectural practitioners are vocal in their complaints about planning officers, - in particular at local authority level, - who are required to make decisions and provide advice to their elected local Councils on building development proposals, yet are not seen to have the pre-requisite skills to make informed judgements on design issues.

Introduction in universities of postgraduate programs at diploma and masters levels in urban design has been one initiative to fill the vacuum. Although the numbers of graduates is very small compared with the output from undergraduate architectural degrees and the various planning programs, many are beginning to find influential places in public authorities and architectural/urban design/planning consultancies. The first such university program was commenced in Australia only in 1989, although some programs in the USA and UK predated this by more than two decades. In the absence of more broadly based surveys the case studies in this paper confirm that there is presently an important role in society for graduates of programs of this type: Circumstantial evidence indicates that in a country with increasing population and growing economy these roles are very likely to increase.

\section{OVERALL CONCLUSION}

There are three generalised but nevertheless significant conclusions which can be drawn from the case studies.

The first is that in the context of a situation in which the role and authority of the architect in many individual large building projects is typically far less influential than it has been in previous eras, architects in official positions and advisory roles are playing a dominant and critical role in structuring, monitoring and reviewing the overall development framework of the city, and of these very large and complex urban projects. This applies to the extent that the basic determinants of building form, - height, alignment, activity and circulation patterns have largely been predetermined before specific development proposals are advanced.

The second is that in pre-determining the formal framework it was the quality and characteristics of the urban context, the nature of the specific places which were given priority. In the case of East Circular Quay it was the unique ambience of the Opera House which dominated the generation of urban design controls, in the Casino the concern that a vast floor area of building should be contained within an envelope which would mediate between the harbourside character and contiguous residential areas, and in Homebush Bay, - a largely undeveloped site, - a commitment to ensuring that a balance would be established between environmental and conservation criteria and the imperatives of a large building program. Rather than any propensity towards a "subverting of the conventions of place", - in the words of the Conference Chair, - the organisational framework has been 
directed towards conserving and enhancing the integrity of each place. Whether or not this objective is ultimately achieved in each case will be a matter of critical review at a future time.

The third is that in the prevailing political and social environment in the city of Sydney, there is strong evidence to suggest that it is more important than ever before that architectural education at undergraduate level should proceed within the context of awareness and understanding of environmental and cultural issues if graduates are to be adequately equipped to respond to roles which are broader than that of the design of the individual building. At postgraduate level the development of urban design skills and research training can be seen to be equally important.

\section{REFERENCES AND NOTES}

${ }^{1}$ Fernand Braudel, The Structures of Everyday Life: the Limits of the Possible, Collins, London, 1981, p.561.

2 Rene Diaz, ACSA European Conference 1995: Call for papers.

${ }^{3}$ NSW Department of Planning, Sydney's Future, 1993, pp.1517.

${ }^{4}$ In the USA the seminal work of Robert Gutman Architectural Practice: A Critical View, Princeton, 1988; in the UK the R.I.B.A. Strategic Study of the Profession, May 1992; and in Australia the RAlA Architects' Share of the Design Market (survey report 1993) evidence the common forces at work in these countries.

5 An overview of the Sydney environment is provided in Webber, Peter, Control Codes, Design Review and Political Compromise: Conclusions from Case Studies in Sydney CBD, Proceedings of the International Symposium on Design Review, University of Cincinnati, 1992, pp.359-370; and Webber, Peter, The Design of Sydney: Three Decades of Change in the City Centre, Law Book Company, 1988.

${ }^{6}$ The CBD of the city is controlled by both Statutory Local Environmental Plans which define activity zones, conservation requirements, and heights, and Development Control Plans which are area, or site-specific and may be subject to negotiated change.
7 Urban Design Unit, Department of Planning, East Circular Quay: Urban Design Study and Guidelines, April 1988.

${ }^{8}$ Mitchell Giurgola Thorp, East Circular Quay Design Assessment: a Report to the Sydney City Council, September 1989.

${ }^{9}$ The competition was termed "Ideas Quest for East Circular Quay" and attracted 206 submissions. The panel of assessors was chaired by distinguished Sydney architect, Kenneth F. Woolley.

${ }^{10}$ Sydney City Council, Planning and Design Principles for East Circular Quay, August 1992. This document set out four pages of primary and secondary principles, and a concise diagram which defined maximum and minimum heights, building alignments, and access requirements.

${ }^{11}$ Architects are Sydney firm Peddle Thorp, with associated architects being involved for specific building components.

12 The statutory plan is known as Regional Environmental Plan No. 26 - City West which is complemented by an advisory document, - the Urban Development Plan for the UltimoPyrmont Precinct.

13 This Plan was prepared by Sydney architect-planners Jackson Teece Chesterman Willis and was endorsed by the Minister in April 1993.

${ }^{14}$ Chair of the Development Advisory Panel is Sydney architectplanner Don Davison: architect members are Kevin Rice and David Chesterman with Professor Webber as urban design adviser.

15 Project architects are Philip Cox, Richardson Taylor in association with US based firm Hillier. Project manager is Sydney based Leighton Properties with the US based casino operator being Showboat Australia.

${ }^{16}$ Executive Manager, Planning and Design is Mr David Churches.

17 Consultant architect-planners to this stage were the Sydney firm of Keys Young.

${ }^{18}$ Composition of the Panel was N. Ingham (planner), R. Simpson (architect) and H. Lochhead, R. Meyer and P. Webber (architect/planners).

19 Urban Design Group membership is L. Nield, Peddle Thorp and Walker, Context Landscape, Conybeare Morrison, Phillip Thalis and Hassel Maher.

20 The University of Sydney program was described in Peter Webber, Urban Design Education and the Seminal Role of the Beginning Project, ACSA/EAAE Conference proceedings, Prague, May 1993, (p.134 Synopsis). 